\title{
The Economics of Offshore Wind
}

\author{
Richard Green and Nicholas Vasilakos* \\ Department of Economics \\ University of Birmingham \\ Birmingham B15 2TT \\ Tel: +441214158216 \\ Email: r.j.green@bham.ac.uk \\ n.vasilakos@bham.ac.uk
}

\begin{abstract}
This paper presents an overview of the main issues associated with the economics of offshore wind. Investment in offshore wind systems has been growing rapidly throughout Europe, and the technology will be essential in meeting EU targets for renewable energy in 2020. Offshore wind suffers from high installation and connection costs, however, making government support essential. We review various support policies used in Europe, concluding that tender-based feed-in tariff schemes, as used in Denmark, may be best for providing adequate support while minimising developers' rents. It may prove economic to build an international offshore grid by connecting wind farms belonging to different countries that are sited close to each other.
\end{abstract}

JEL Codes: D43, L13, L94, Q41, Q42

Keywords: offshore wind power, cost analysis; market trends.

\footnotetext{
* This research is funded by the Engineering and Physical Sciences Research Council and our industrial partners, via the Supergen Flexnet Consortium, Grant Number EP/E04011X/1. It has also been supported by Advantage West Midlands and the European Regional Development Fund through the Birmingham Science City Energy Efficiency Project. We would like to thank an anonymous referee, David Toke and participants at the conference on Offshore Wind Power, held in Birmingham in August 2009, for helpful comments. The views expressed are ours alone.
} 


\section{Introduction}

Over the past decade, many countries have invested heavily in wind power, and current energy policies imply that there is a lot more investment to come. Most existing wind farms have been built on land (onshore) but some countries in north-west Europe have also started to invest in offshore wind, and the UK (in particular) has aspirations for offshore wind farms to make up nearly one-third of its generating capacity in the 2020s. This is in the context of the EU's demanding targets for renewable energy - 20 per cent of final energy demand is intended to come from renewables by 2020 , and this could mean that one-sixth of Europe's electricity comes from wind. ${ }^{1}$

Why would governments be interested in promoting offshore wind farms? Higher and steadier offshore winds make offshore wind farms more productive (UK figures suggest a capacity factor of about $36 \%$ compared to an average of $27 \%$ for onshore wind farms (Boyle, 2006)), which in turn implies a higher capacity credit, and thus smaller back-up costs (Milborrow, 2009). Against this, the costs of building offshore are much higher, and there are bottlenecks in the supply chain, mostly due to the relatively limited number of installation vessels and the long queues in suppliers' order books due to the (so far) limited production volumes of equipment and parts (Krohn et al, 2009). In the UK context, where many onshore wind farms have been delayed or blocked by difficulties in getting planning permission, the lower visual and other impacts of offshore wind farms are important, and they can offer the flexibility to locate closer to (some) load centres, thus helping to reduce transmission losses and avoid congestion bottlenecks. Even if there were no problems in getting planning permission, the physical space available for onshore turbines in the UK is limited, and building offshore allows a significant increase in the total potential contribution (MacKay, 2008).

\footnotetext{
${ }^{1}$ The European Commission (2007) has produced a scenario in which wind power provides $41 \%$ of the renewable electricity generation, which in turn makes up $43 \%$ of total generation, giving an overall proportion of $17 \%$. The relative ease of producing renewable electricity implies that it will provide much more than $20 \%$ of the final demand for power, while the proportion of renewable energy in transport (in particular) will be well below $20 \%$.
} 
This paper discusses the economic implications of the move to offshore wind. Section 2 illustrates the dramatic increase in capacity and generation over the last decade, and the even faster rise predicted for the next. This comes despite the higher cost of building stations offshore than onshore, discussed in section 3. Additional costs come from the need to use subsea cables to connect the stations to the transmission system, raising issues which we cover in section 4 . The following section concentrates on the interaction between wholesale markets and the output from offshore wind farms, showing that they are at risk of earning less than the time-weighted average price of power, should they depend on wholesale market revenues. Given this, and their high costs, government support is likely to be needed for many years to come. Section 6 discusses the main ways of supporting offshore wind stations. Finally, section 7 concludes.

\section{Offshore wind: current status and plans}

New investment in offshore wind generation capacity has shown a remarkable increase, particularly in Europe, over the last two decades. Total offshore installed capacity in Europe has increased from under 50MW in 2000 to about 1,471 MW by the end of 2008 (EWEA 2009), translating to an average annual rate of growth of about $50 \%$ per year. Although currently the bulk of operating offshore systems concentrates within a small number of Northern European countries, the interest in offshore wind farms is widening rapidly around the world.

Currently, most of the existing installed offshore capacity concentrates within a handful of Northern European countries: the UK, Denmark and the Netherlands. As of 2008, these three countries accounted for $85 \%$ of the EU-27 offshore wind capacity (their corresponding combined share for onshore capacity was just over 11\%). In particular, the UK had the highest total installed offshore capacity, with 591MW followed by Denmark (409 MW) and the Netherlands (247 MW). Although these shares are likely to decrease over the coming years, as investment in offshore starts to catch up in the rest of Europe, the UK is expected to maintain its current leading position in this market. 
Indeed, the UK's share of total EU offshore capacity is predicted to be around 30\% in 2020, according to the National Allocation Plans submitted to the European Commission by September 2010. These imply a total offshore capacity of $43 \mathrm{GW}$, and $13 \mathrm{GW}$ from the UK, while the available figures for onshore capacity add up to $155 \mathrm{GW} .^{2}$

Despite its spectacular growth, the current share of offshore capacity remains relatively low when compared to operating onshore (and just over 2\% of total wind capacity for EU27). The higher costs associated with offshore wind farms, as well as supply chain bottlenecks (mainly attributed to yet small scale production of turbines - implying capacity limitations - and the limited availability of suitable installation vessels, Musial and Butterfield, 2004) are often seen as the main drivers behind this gap. As interest in the market expands both of these constraints are becoming increasingly less binding, and the supply chain is now showing signs of catching up with demand.

EWEA (2009) provides “conservative” (low) and “ambitious” (high) scenarios about the total number of wind onshore and offshore installations by 2020. According to these figures, the conservative scenario suggests an increase of total offshore wind installations in EU-27 to over 19\% of total wind power capacity, that is $40 \mathrm{GW}$ of offshore and nearshore wind installations. According to this scenario, the UK is expected to increase its share of capacity derived from offshore wind farms from 2.65 GW in 2008 to 13 GW in 2020 (thus deriving 50\% of its total wind capacity offshore). The "high" scenario suggests that the share of offshore wind will increase to $22.7 \%$ of total wind capacity in EU-27, with the UK's share now assuming the value of 58.82\% (20 GW). In both scenarios, the UK is expected to maintain its current leading position in offshore wind generation, followed by Germany with a total offshore capacity of 8-10 GW. The details of the current shares and EWEA's estimates for 2020 for EU-27 are summarised in table 4.

\footnotetext{
${ }^{2}$ At the time of writing (September 2010), eight of the National Allocation Plans are missing from the Commission's web site (http://ec.europa.eu/energy/renewables/transparency_platform/action_plan_en.htm); three of these are from landlocked countries and could not contain any offshore wind capacity.
} 


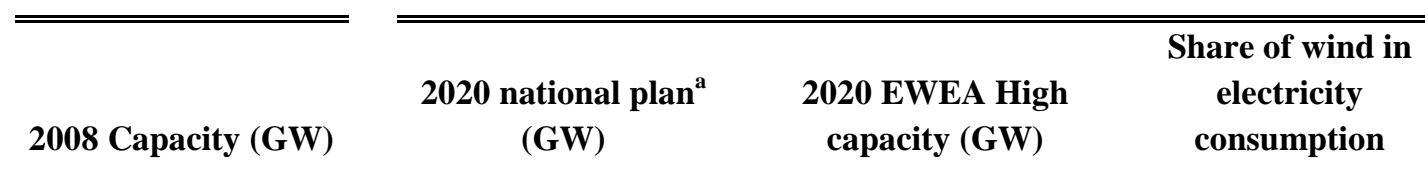

\begin{tabular}{|c|c|c|c|c|c|c|c|c|}
\hline Country & Onshore & Offshore & Onshore & Offshore & Onshore & Offshore & 2008 & 2020 high \\
\hline$\overline{\mathrm{UK}}$ & 2.7 & 0.59 & 14.9 & 13.0 & 14.0 & 20.0 & $2 \%$ & $25 \%$ \\
\hline Germany & 23.9 & 0.01 & 35.8 & 10.0 & 42.0 & 10.0 & $7 \%$ & $17 \%$ \\
\hline France & 3.4 & - & 19.0 & 6.0 & 20.0 & 6.0 & $2 \%$ & $11 \%$ \\
\hline Netherlands & 2.0 & 0.25 & 6.0 & 5.18 & 5.4 & 6.0 & $4 \%$ & $22 \%$ \\
\hline Sweden & 0.9 & 0.13 & 4.37 & 1.82 & 8.0 & 3.0 & $2 \%$ & $16 \%$ \\
\hline Denmark & 2.8 & 0.41 & 2.62 & 1.34 & 4.0 & 2.5 & $20 \%$ & $46 \%$ \\
\hline Belgium & 0.4 & 0.03 & $\underline{2.1}$ & $\underline{1.8}$ & 2.5 & 2.0 & $1 \%$ & $12 \%$ \\
\hline Spain & 16.7 & - & 35.0 & 3.0 & 41.0 & 1.5 & $12 \%$ & $26 \%$ \\
\hline Finland & 0.1 & 0.02 & 2.5 & $0.0^{\mathrm{b}}$ & 2.0 & 1.0 & $0 \%$ & 8 \\
\hline Ireland & 1.0 & 0.03 & 4.1 & 0.6 & 6.0 & 1.0 & $9 \%$ & $55 \%$ \\
\hline Italy & 3.7 & - & 12.0 & 0.7 & 17.0 & 1.0 & $2 \%$ & $9 \%$ \\
\hline Poland & 0.5 & - & $\underline{10.0}$ & $\underline{0.5}$ & 12.0 & 0.5 & $1 \%$ & $15 \%$ \\
\hline Greece & 1.0 & - & 7.2 & 0.3 & 8.3 & 0.2 & $4 \%$ & $29 \%$ \\
\hline Estonia & 0.1 & - & $\underline{0.5}$ & $\underline{0.0}$ & 0.5 & 0.1 & $2 \%$ & $11 \%$ \\
\hline Latvia & 0.0 & - & $\underline{0.2}$ & $\underline{0.0}$ & 0.2 & 0.1 & $1 \%$ & $9 \%$ \\
\hline Lithuania & 0.1 & - & 0.5 & 0.0 & 1.0 & 0.1 & $1 \%$ & $13 \%$ \\
\hline Others & 4.3 & - & 11.3 & 1.0 & 26.1 & - & & \\
\hline EU-27 & 63.5 & 1.47 & 168.1 & 45.2 & 210.0 & 55.0 & $4 \%$ & $17 \%$ \\
\hline
\end{tabular}

Table 1: Offshore and Onshore wind capacities in EU-27.

a entries underlined were for the EWEA's low scenario, as National Renewable Energy Plans were not available for these countries

${ }^{\mathrm{b}}$ The National Plan for Finland does not give separate figures for onshore and offshore wind

Source: National Renewable Energy Plans 2010, EWEA - Pure Power: Wind Energy Scenarios up to $2030(2010)$ 
The value of investment in offshore wind follows a similar pattern to the one described for installed capacity and is shown in figure 1 . Assuming the capacity prices suggested by the EWEA (1,250 €/kW for onshore and 2,400 €/ kW for offshore, in 2005 constant prices, EWEA 2009) and the "conservative” ("low scenario”) capacity targets summarized in table 1, investment in offshore wind capacity is expected to grow from its current value of about $€ 2$ billion per year to just under $€ 9$ billion in 2020, reaching over $€ 16$ billion in 2030. EWEA expects the market for onshore capacity in Europe to start showing signs of saturation after 2020, partly due to a deceleration in the demand for onshore turbines (e.g. due to utilisation of productive sites) and partly due to a shift in interest to the more productive (and by that time more cost efficient compared to present) offshore generation. As a result, EWEA expects offshore investment to overtake onshore in about 2023.

\section{Figure 1: Predicted wind capacity investments in Europe}

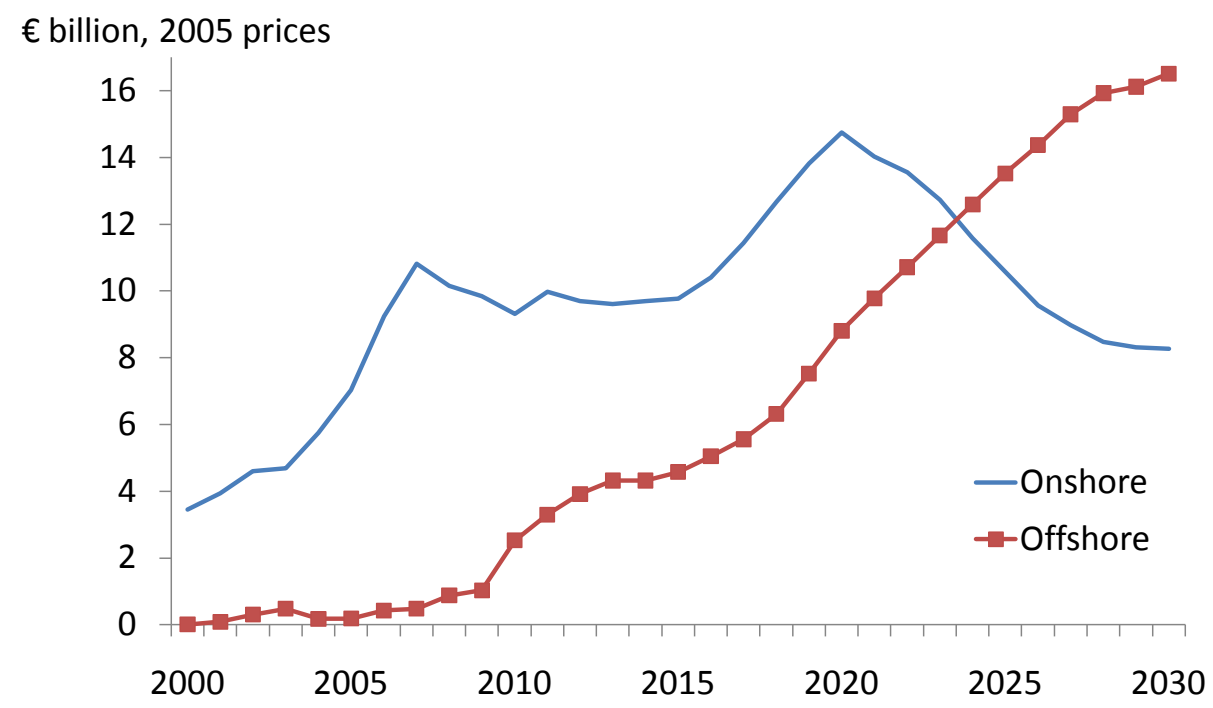

Source: EWEA (2009) 


\section{Costs of offshore wind}

As with most new technologies, one of the factors that determines the speed with which it is deployed and established is the cost curve that is associated with its usage. The costs for offshore wind generation have indeed been significantly higher throughout than for onshore wind farms, although recent technological improvements in the size and design of turbine technology and, in general, more efficient production patterns, may have the potential to narrow this gap. In recent years, however, offshore wind costs have risen rather than falling, driven partly by increasing material prices (particularly for steel) and partly by a rapidly rising demand relative to supply chain capacity (Greenacre et al, 2010). Excess supply (due to slow growth rates of new investment) over the period 2001-2004 was followed by a period during which the market grew by an average of 35\% per annum, leading to capacity shortages, long order books for manufacturers and thus resulting to a price surge. These factors are likely to remain relevant in future: BWEA and Garrad Hassan (2009) derive predicted costs of between $£ 2,300 / \mathrm{kW}$ and $£ 3,900 / \mathrm{kW}$ in 2015, depending on whether the overall economy is growing or in recession, the level of (competing) investment in onshore wind, and the level of confidence with which the offshore supply chain develops.

EWEA (2008) develops estimates about the capacity costs of offshore and onshore wind installations for up to 2030, taking into account the recent data on the price, demand and supply of turbines. According to these figures, the average capital cost for a $\mathrm{kW}$ of offshore wind to be installed in 2009 was in the region of $€ 2,300$, compared to $€ 1,300 / \mathrm{kW}$ for onshore capacity. These figures are comparable to the estimates presented in McDonald (2010), ranging between $£ 1,335 / \mathrm{kW}$ - $£ 1,680 / \mathrm{kW}$ onshore and $£ 2,320-£ 3350 / \mathrm{kW}$ for $\mathrm{n}$-th of a kind offshore wind turbines. Of course, the level of capital costs is affected by geographical factors and hence variations by location are to be expected. Blanco (2009) offers a comprehensive survey of the factors that influence the cost estimates for onshore and offshore wind turbines and uses a sample of wind energy manufacturers to estimate average generation costs for onshore and offshore farms. Capital costs in her study are found to vary between $€ 1,100 / \mathrm{kW}$ - €1,400/kW onshore and $€ 1,800 / \mathrm{kW}$-€2,500/kW offshore. Although the investment costs for onshore wind are also expected to fall over time, the price of offshore capacity is 
expected to fall faster, as scale economies are achieved by manufacturers, bottlenecks in the supply chain are further eased and newer, larger turbines are put to use enabling higher efficiency. Figure 2 visualises EWEA's scenario for the evolution of cost of offshore and onshore investment up to 2030.

\section{Figure 2: Past and predicted wind capacity costs}

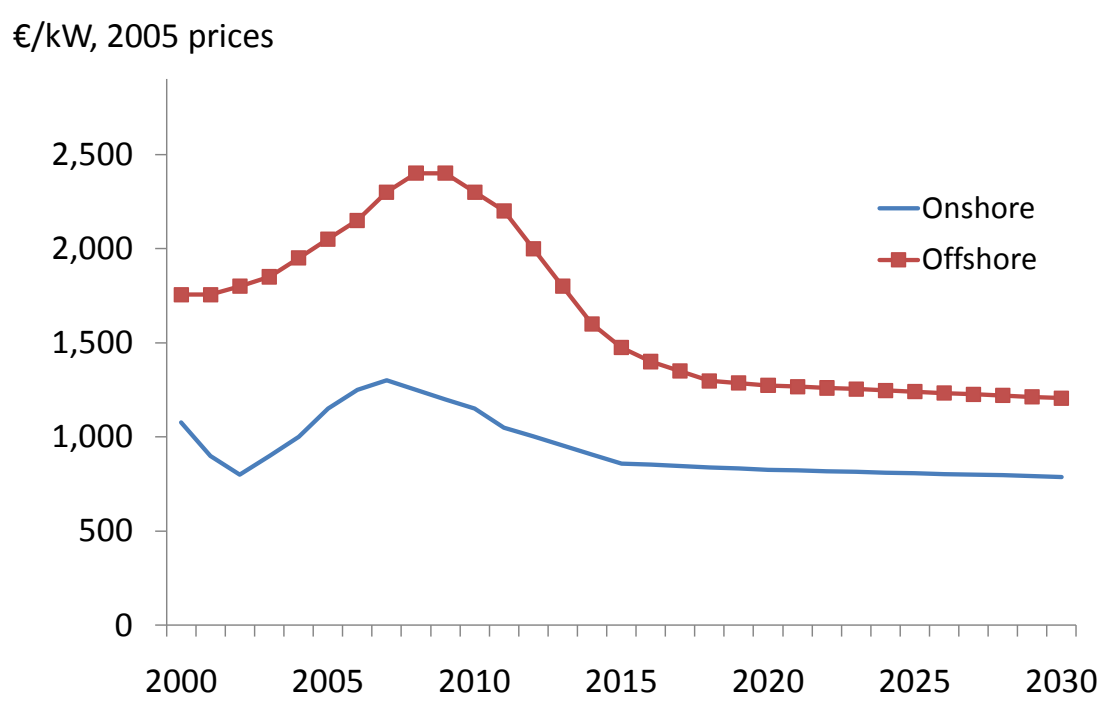

Source: EWEA (2008), Annex 5

These cost differences for offshore and onshore wind stations are often attributed to factors associated with the design, building and transmission of offshore stations. For instance, laying foundations for an offshore (or nearshore) wind station can be 50\% more expensive (or more) than for a conventional land-based turbine. The exact level of the cost premium depends on factors including water depth and distance from shore. Recent cost data collected from the two largest Danish offshore wind farms (the Horns Rev project and the Nysted offshore wind farm) suggests that foundations for offshore wind turbines can claim as much as $21 \%$ of total cost expenditure ( as against $5-9 \%$ for onshore turbines, EWEA, 2009). 
Table 2: The impact of depth and distance on costs

\begin{tabular}{|l|l|l|l|l|l|l|l|l|}
\hline \multirow{2}{*}{ Water } & \multicolumn{7}{|c|}{ Distance from shore (km) } \\
\cline { 2 - 9 } & $0-10$ & $10-20$ & $20-30$ & $30-40$ & $40-50$ & $50-100$ & $100-200$ & $>200$ \\
\hline $10-20$ & 1 & 1.02 & 1.04 & 1.07 & 1.09 & 1.18 & 1.41 & 1.60 \\
\hline $20-30$ & 1.07 & 1.09 & 1.11 & 1.14 & 1.16 & 1.26 & 1.50 & 1.71 \\
\hline $30-40$ & 1.24 & 1.26 & 1.29 & 1.32 & 1.34 & 1.46 & 1.74 & 1.98 \\
\hline $40-50$ & 1.40 & 1.43 & 1.46 & 1.49 & 1.52 & 1.65 & 1.97 & 2.23 \\
\hline
\end{tabular}

Source: EEA (2009)

All costs increase significantly with distance from shore and water depth, as shown in table 2. The table shows the adjustment factor by which investment and installation costs (based on a turbine close to shore in shallow waters) should be multiplied for deeper water and greater distances. This relationship between water depth and costs has discouraged the development of deep-water turbines, despite the extra productivity benefits that are often achieved from distance to shore (due to higher wind speeds). Indeed, at present, operating wind farms tend to be located no further than $20 \mathrm{~km}$ from shore and in water depths of no more than 20m (EWEA, 2009). Future developments will involve greater distances and depths - the UK's Round Three includes the Dogger Bank, almost 200 km from shore, and with a maximum depth of 63 metres. The costs of building and maintaining wind turbines in these conditions will be significantly higher than those in easier waters, especially when we consider the need to connect them to the main electricity system onshore. 


\section{Connecting Offshore Wind to the Grid}

All new generators will need a connection to the electricity network, and this will be particularly challenging for offshore wind farms. ${ }^{3}$ First, subsea cables are much more expensive (per km) than overhead transmission lines. Second, some of these cables will have to travel long distances to a suitable point on the transmission system, and will then still be a long way from the main centres of demand. Third, a cable connecting a particular generator can only be used when that generator is actually producing, and we have already seen that wind stations have relatively low load factors, increasing the average cost per MWh generated. Some economies are possible by building a wind farm slightly larger than the capacity of the cable (cables come in fixed capacities that are many times bigger than a typical wind turbine ${ }^{4}$ ) as the wind farm will rarely generate at full capacity. National Grid (2008) have calculated that the optimal balance between reducing the connection cost per generator and increasing the amount of electricity that has to be spilled (when generation does exceed the capacity of the cable) is obtained with a wind farm capacity that is $112 \%$ of its connection capacity. Even so, with a station load factor of around $40 \%$, the connection assets will be used at less than half of their capacity, on average. National Grid have estimated the cost of connecting 19 GW of offshore wind farms to be between $£ 6$ billion and $£ 10$ billion (House of Lords, 2008, para 121). The top half of this range exceeds the (partly depreciated) regulatory asset value of the entire current transmission system, which is $£ 7.5$ billion (Ofgem, 2006, pp. 92-94).

This makes it particularly important to minimise the cost of connecting offshore wind farms to the grid. There are two offsetting concerns. First, if many different connections are designed piecemeal, early decisions may affect the costs of the schemes that are connected later - and those may well be the larger, more expensive, projects. Second, a monopoly developer will be under less pressure to keep costs down than a group of competing companies. The first concern suggests that there should

\footnotetext{
${ }^{3}$ Again, data from Horns Rev and Nysted show that the average cost of transmission claimed a share of $21 \%$ compared to an average 5\% for land-based farms.

${ }^{4}$ The cost of the cable depends much more on its length and on the terrain it must traverse than on its capacity, which reduces the cost per MW for larger wind farms, up to the maximum capacity of a cable.
} 
be an overall development plan taking account of the interactions between projects, and with the existing onshore grid. This would have to be prepared by, or in close collaboration with, the onshore transmission operator. The second concern might suggest that a single onshore operator should not automatically be allowed to develop the individual connections that the development plan requires.

One obvious way of organising this would simply be to allow each wind farm's developer to be responsible for connecting their station to shore, following the overall development plan, just as they are responsible for building the station itself. The developer has a strong financial incentive in obtaining a cost-effective connection - high costs or low availability will directly affect its profits from the station. The early British wind farms used this approach, but their regulator has decided that it falls foul of the EU Third Electricity Directive, which requires a high degree of separation between generation and transmission activities. ${ }^{5}$ In future, the regulator will run tenders to appoint the Offshore Transmission Owner (OFTO) which will build, own and operate the connection assets for each wind development zone. The Crown Estate, which is responsible for the economic use of the seas around the UK, has appointed a single lead developer for each of these zones, which allows for coordination between that developer and the OFTO for the zone. OFTOs will also be appointed for the existing stations, paying their developers to take over the connection assets those developers have built.

However the OFTO has acquired its assets, the generator will pay for their use through the main system of regulated transmission tariffs used in Great Britain. Generators pay a charge per kW of capacity which is based on the impact of their output on peak flows through the grid. Charges have been calculated based on the number of MW-km of extra capacity required to accommodate the output from stations located in different zones on the network - the further a station is from the main

\footnotetext{
${ }^{5}$ If the same company owns both generation and transmission, a fully independent transmission system operator must be appointed to ensure that the transmission system is not run in a way that might be anti-competitive. It should be noted that other countries take a different view of the Directive's requirements: in Sweden, for example, a wholly-owned subsidiary of the developer (Vattenfall) runs the transmission connection for the Lillgrund offshore wind farm (Söderberg and Weisbach, 2008).
} 
demand centres, the more capacity would be needed, and the higher its charge. The same principle will be used in future, but new zones will be set up so that each offshore generator pays its own specific charge. The modelled length of the line between the offshore zone and the rest of the transmission system will be calibrated to ensure that the OFTO for that zone recovers an amount of revenue dependent on its tender bid. This will be equivalent to the offshore generator paying a connection charge to the OFTO, based on the cost of connecting it to the main onshore grid, and also paying the onshore transmission companies for the use of their systems, taking the onshore connection point as the generator's "location".

One potential disadvantage of the OFTO approach, with (potentially) different companies running the connections for neighbouring wind farms, is that it will be harder to arrange for wind farms to share connections. Could this be a major issue in practice? The opportunity to share transmission assets is one thing that keeps down the cost of the onshore grid - a properly planned system does not need the transmission capacity to run every power station at once, because generating capacity should significantly exceed the peak demand, and so we would never experience every power station running simultaneously. The best level of transmission capacity between two zones is based on the largest likely transfers between them, not on the total generation in the exporting zone. Could this lead to a similar saving for offshore lines, connecting several stations to an offshore grid? Early, small, wind farms had capacities that were typically too small to make full use of a single transmission cable, with the implication that it would be worth building short spurs between nearby wind farms (if any) in order to make better use of the main cable to shore. The wind farms now being planned, however, are much larger, and will need several cables to bring their power to shore. There could still be savings in capacity if two farms expected to have different generation patterns shared their connections. The optimal capacity for the two stations together would be less than the sum of their individual needs if there would be few times when both stations were generating at high output levels. The problem is that if the wind farms are to be close enough to connect them without greatly increasing the length of cables, they are likely to have very similar wind conditions, and hence output patterns. 
A second possibility for an offshore grid is to transfer power between the countries on two sides of a sea. This would not make sense for wind farms close to shore, but some will be nearly halfway between two countries. The cost of a cable from the wind farm to the "foreign" country may be significantly lower than the cost of a cable for the full distance between the two countries. It would give the wind generator the option of exporting its power in either direction, wherever the market price is higher. When the wind farm is not generating (or not generating as much as the cable’s capacity) power can be transmitted from one country to the other. The ability to move electricity from countries with a surplus to those with a shortage will become increasingly important as the levels of intermittent renewable generation increase. It is already the case that fluctuations in Denmark's wind generation are strongly correlated with fluctuations in its net exports (Green and Vasilakos, 2010b) and international transfers are important in balancing the system. They will also tend to reduce short-term fluctuations in electricity prices and medium-term differences between countries. ${ }^{6}$

This will remain the case, even if the transfers are made between countries with large amounts of wind power, since the relative variation in wind output falls, the larger the area covered. Østergaard (2008) shows this for the case of East and West Denmark; Drake and Hubacek (2007) derive an optimal portfolio of offshore wind farms around the UK, showing that a $36 \%$ reduction in the standard deviation of hourly output can be achieved, albeit at the cost of $9 \%$ less output than concentrating production at the windiest site. Roques et al (2010) calculate optimal wind portfolios across five European countries (Austria, Denmark, France, Germany and Spain), taking resource and transmission constraints into account. Their optimal portfolios would give between three and six per cent more output (for given variances) than current projections for the distribution of wind power across these countries in 2020.

\footnotetext{
${ }^{6}$ De Jonghe et al (2008) show that the increased cross-border trade that followed the introduction of the trilateral market coupling between France, Belgium and The Netherlands led to price convergence between France and The Netherlands, and a reduction in the volatility of Dutch electricity prices.
} 
The question that is particularly relevant for offshore wind is not whether international interconnections are a good thing, but whether they should be made via wind farms. The saving in cable costs needs to be considered against the lower availability of the cable for trade. If the wind farm has a load factor of just over $40 \%$ (and a slightly greater capacity than the cable, as recommended above), then less than $60 \%$ of the cable’s capacity will be available for trade, on average. If the wind farm was nearly midway between the countries, this $60 \%$ of capacity might be obtained for roughly $50 \%$ of the cable costs of a standalone interconnector. Since the cable would still need to be connected to the wind farm and the foreign grid onshore, the cost saving may not be as great as the loss of usable capacity. In other words, if it is worth paying $60 \%$ of the cost to get a cable between two countries available $60 \%$ of the time, it may well be worth paying the full cost for a cable that is available all the time. The presence of a single offshore wind farm should not significantly change the cost-benefit analysis on an interconnector.

The economics change dramatically if there are two offshore wind farms in close proximity that would otherwise be connected to different countries. In this case, the marginal cost to interconnect the two countries is the cost of connecting two nearby wind farms, well below the cost of connecting a wind farm directly to the foreign country. In the Baltic Sea, Germany is building a wind farm on Kriegers Flak, and Denmark is likely to follow suit; Sweden may build a third wind farm nearby in due course. A feasibility study conducted for the three transmission system operators shows that the cost of connecting the three wind farms, and increasing the possible power transfer from Denmark and Sweden by building a second line to Germany, would be less than the economic benefit of doing so (50 Hertz Transmission et al, 2010). The central estimate of the additional costs of the additional connections had a present value (at a 6\% real interest rate) in 2010 of around $€ 350$ million, with benefits of between $€ 400$ million and $€ 1400$ million, depending on the model used. This shows that, in the right place, an offshore grid to connect nearby wind farms can have significant benefits, but there may be few locations as well-sited as Kriegers Flak. 


\section{Offshore wind and the wholesale market}

As pointed out in the earlier sections, the amount of investment in offshore wind generation is expected to increase significantly over the next two decades. Some of the latest EWEA forecasts suggest that by 2030 as much as $50 \%$ of total wind capacity maybe installed offshore. With such large amount of extra wind installations coming online in a relatively short period of time, a relevant question to ask is how they are going to affect electricity prices and overall market structure of the industry.

The impact of increased amounts of intermittent generation on prices and market structure has been discussed in a number of recent papers, although the majority of them are based on the current situation, with most investment located onshore. de Miera et al (2008), Munksgaard and Morthorst (2008), and Sensfuß et al (2008) assess how increased levels of wind penetration will affect wholesale market prices in Spain, Denmark and Germany, respectively. Both studies find that increasing wind capacity lead to lower prices by reducing the average demand for thermal (and higher marginal cost) generation, but did not consider any longer-term changes to the capacity mix. ${ }^{7}$ Green and Vasilakos (2010a) make a forward-looking projection for Great Britain, based on a scenario with a large amount of offshore wind power. They use hourly data on windspeeds for a number of representative weather stations over a 13-year period to simulate the impact of a high level of intermittent output on electricity prices and generators revenues for Great Britain. Demand levels were calibrated to possible levels for 2020, when they assume that there would be 19 GW of offshore wind capacity, compared to $11 \mathrm{GW}$ onshore. Their findings suggest that as the amount of wind penetration increases, so does price volatility and that this impact is exacerbated further in the presence of market power. The effect of market power on price volatility is also discussed by Twomey and Neuhoff (2010), who present a theoretical framework which explains that market power can lead to higher levels of revenue volatility for renewable generators, because the margins between

\footnotetext{
${ }^{7}$ Green and Vasilakos (2010c) show that in a long-term equilibrium, changes to the capacity mix of thermal plant will tend to offset the impacts of wind power on prices, producing a broadly similar price-duration curve.
} 
price and marginal cost are likely to be at their highest when thermal demand is high (that is, during periods with low wind output), and lower when during the hours of the day that the wind blows.

The volatility of prices in response to renewable output is a problem for wind generators, for their output is greatest at the times when it is depressing prices. This reduces their average revenue (if based on market prices) below the time-weighted average of wholesale prices, and well below the demand-weighted average received by thermal stations. The prices simulated by Green and Vasilakos (2010a) had a time-weighted average of $£ 35.45 / \mathrm{MWh}$ in a (relatively) competitive scenario, but onshore wind stations would receive only £33.59/MWh. Offshore stations do even worse, receiving $£ 32.42 / \mathrm{MWh}$ on average. This is because many of those stations are predicted to be in a similar area of the North Sea with (as modelled, based on a single weather station) identical output patterns. When these stations are generating, they have a big impact on the power price, which reduces their average revenues. Smaller stations, on- or offshore, have much less individual impact on the wholesale price, and although they do suffer from the impact of other wind stations' outputs (since these are correlated) this is a less important effect. While this would tend to imply that there are benefits from finding a site a long way from other wind generators, thus minimising the correlation between the station's own output and that from the rest of the industry, the least fortunate stations received only 5\% less per MWh than the best in these simulations. The impact of wind conditions on the station's annual output will have a much more important effect on its profits.

The current evidence on the productivity of "typical” offshore and onshore based turbines suggests that the former do indeed benefit from a significantly higher number of full load hours per year (about 4,000 compared to about 2,500 for onshore (Krohn et al, 2009)), though of course the actual performance is strictly dependent on the locational characteristics of the offshore farm. Deeper water farms tend to achieve higher productivity rates, but at a higher overall investment cost. These differences in the actual distribution of wind output in onshore and offshore locations throughout the day will determine the actual market impact of large amounts of offshore investment on prices and revenues. 


\section{Supporting offshore wind}

From the information on costs given above, it is clear that there would be little investment in offshore wind in the absence of specific policy support - very high fossil fuel prices would be needed to make offshore wind competitive against conventional plants, and offshore stations would still be more expensive than onshore wind (at reasonable sites). Nonetheless, several European governments are counting on investment in offshore wind in order to meet their targets for renewable energy production, and are supporting it accordingly.

Two main approaches for supporting renewable energy are currently being used in Europe, as shown in table 2, which gives the schemes used specifically to support offshore wind. Under a feedin tariff, the policy-maker sets a fixed price which is paid for every qualifying unit of electricity. The price can depend on the technology used to produce the power, on the year in which the station was commissioned (later stations often receive a less generous price) and even on the local wind conditions. (Germany pays a lower price for electricity generated at sites with the best wind conditions. This might seem counter-intuitive, but if the national targets require that less windy sites are also developed and the feed-in tariff makes this (just) profitable, then paying the same tariff for power produced at better sites would give excessive returns to those generators. One advantage of the feed-in tariff is its relative simplicity, which has allowed consumers, cooperatives and small firms to assume a major role in onshore wind in Denmark and Germany; however, the offshore sector in these countries is dominated by larger firms (Markard and Petersen, 2009). ${ }^{8}$

Under a system of tradable green certificates, renewable generators receive certificates for each unit that they generate, and electricity retailers (typically) are required to surrender certificates equal to a set proportion of the power they sell. Retailers with insufficient certificates can buy themselves out, and the level of this buy-out price determines the value of the certificate. (The

\footnotetext{
${ }^{8}$ This may be a consequence of the relative immaturity of the offshore wind sector, or a permanent feature related to the higher costs involved.
} 
certificate may be worth more than the buy-out price, as holders of the UK's Renewables Obligation Certificates are entitled to receive a pro-rata share of the buy-out payments, creating a ROC price based on the expected payment avoided plus the share to be received.) As with a feed-in tariff, different technologies may receive different numbers of certificates per unit generated, giving greater support to the more expensive generators. Alongside the certificate, the generator also sells its power, and can expect to receive a market price for this.

Hybrid schemes are also possible. In Spain, the system of support for most renewable generators has moved from a pure feed-in tariff, to a fixed premium on top of the market price, to a premium that is adjusted to keep the generator's overall revenue within a particular range (Klessmann et al, 2008). While the pure feed-in tariff remained available to the generators that had signed up to it, the premium was set at a level that made most willing to change to it. The UK government has promised to keep the size of the Renewables Obligation a fixed percentage above the expected level of generation. This should have the effect, as with a feed-in tariff, of providing the same level of support to any volume of generation (until the policy is changed). ${ }^{9}$ The (previous) government had also suggested that it should offer fixed price contracts (or contracts for differences) to hedge renewable generators' revenues from selling energy, thus further reducing the variation in their revenues. ${ }^{10}$

The advantage of these hybrid schemes is that they reduce the generators' revenue risks, compared to a pure certificate scheme, while still providing some more market exposure than the pure feed-in tariff. If lower risks lead to a lower cost of capital, this will be particularly useful for wind farms, since the cost of construction is such a high proportion of the station's lifetime costs. The European Commission (2008), drawing on work by Ragwitz et al (2007), has assessed the effectiveness (in promoting increases in renewable generation) and efficiency (in terms of avoiding

\footnotetext{
${ }^{9}$ With a standard green certificate system, which requires a fixed amount (or proportion) of power, the price of certificates will fall (perhaps precipitately) as the amount of generation nears the level of the obligation.

${ }^{10}$ A number of respondents to the consultation on this policy opposed it, and since the government changed after the 2010 election, it is quite possible that the idea will be dropped.
} 
excessive generator profitability) of renewable support schemes across the EU, concluding that "welladapted feed in tariff regimes are generally the most efficient and effective support schemes for promoting renewable electricity” (page 3 , italics in original).

The difficulty in setting a feed-in tariff is that if the level is too high, generators will make excessive profits, whereas if it is too low, little or no development will take place. When a technology is well-developed, it is relatively easy to identify the appropriate level of the tariff, and to adjust it (for new generators) to encourage or discourage further investment. When the technology is relatively new, however, this information may not be available. One possibility, adopted in Denmark, is to run a tender for new projects. This requires the generators to bid for the right to develop the project. As with any auction, this can be an efficient way of discovering the value of a scarce resource and allocating it to the most appropriate party, as long as the costs of participation are sufficiently low to attract a reasonable number of competing bidders.

Table 2: Support for Offshore Wind

\begin{tabular}{|l|l|}
\hline Country & Main support policy \\
\hline Belgium & $\begin{array}{l}\text { Supplement to market price of €107/MWh for output from the first } 216 \\
\text { MW in a concession, and €90/MWh for additional output. Formally } \\
\text { organised as green certificates, which transmission operator must buy. }\end{array}$ \\
\hline Denmark & $\begin{array}{l}\text { Feed-in tariff to supplement the market price, with the level set by } \\
\text { price) of DKK 518/MWh; for Rødsand 2, DKK 629 /MWh. }\end{array}$ \\
\hline France & Feed-in tariff of €130/MWh for ten years, falling (except for stations \\
& with bad wind conditions) for the next ten years \\
\hline Germany & Feed-in tariff of $€ 150 / M W h$ \\
\hline
\end{tabular}




\begin{tabular}{|l|l|}
\hline Italy & $\begin{array}{l}\text { Tradable Green Certificates, with offshore wind earning 1.1 certificate } \\
\text { per MWh (10\% more than onshore wind) }\end{array}$ \\
\hline The Netherlands & Feed-in tariff (but market price if this exceeds the tariff) \\
\hline Sweden & $\begin{array}{l}\text { Tradable Green Certificates (worth about SEK 300/MWh in 2009, } \\
\text { although prices fluctuate) }\end{array}$ \\
\hline United Kingdom & $\begin{array}{l}\text { Tradable Green Certificate - offshore wind farms commissioned by } \\
2014 \text { will receive 2 Renewables Obligation Certificates (ROCs) per } \\
\text { MWh of output; each ROC can be sold for around £50 at present. }\end{array}$ \\
\hline
\end{tabular}

Source: International Energy Agency, Global Renewable Energy Policies and Measures database

\section{Conclusion}

It is clear that a number of EU countries will need to make significant investments in offshore wind power if they are to meet their targets for renewable energy in 2020. These stations will be expensive, but they will be more expensive than necessary if the recent sellers' market continues. Governments must help the industry to develop the supply chain for offshore wind power, so that construction costs and margins can fall. Even so, most offshore wind farms will require financial support, unless fossil fuel and carbon prices reach, and stay at, very high prices. European experience suggests that a feedin tariff offers more cost-effective support than a tradable green certificate, because it is less risky and allows these capital-intensive projects to be viable with a lower cost of capital. The problem with feed-in tariffs is the need to set the tariff at an appropriate level, and the risk that it will be too generous, creating excessive rents for well-sited generators, or too mean, stifling development. The costs of offshore wind farms are likely to be much more diverse than those of most other renewable technologies, raising this risk. The Danish support method, which uses competitive bids to set the 
tariff actually required by each developer, has the prospect of minimising the cost of support, while still ensuring that projects remain viable.

Many offshore wind farms could conceivably build a second line to another country, allowing them to sell their output in whichever market offers the higher returns. Where offshore farms connected to different countries are located close to each other, this could be a cost-effective way of building an interconnector between those countries. At times when the wind farms do not need to use the line (and they will typically occupy less than half of its annual capacity), traders can move power from whichever country has lower prices to the other. As the proportion of Europe's electricity generated by wind rises, differentials between short-term prices are likely to rise, making interconnectors much more profitable. Where a wind farm is located between two countries, but not close to a wind farm from the foreign country, it is unlikely that its presence will aid the development of an interconnector by a significant amount. The line needed by the wind farm will indeed reduce the net cost of the interconnector, but it will also reduce its availability for trading between the two countries. If the interconnector with reduced cost and reduced availability is economic, it is likely that a dedicated line for international trade, by-passing the wind farm, would also be a worthwhile investment. Europe will need more interconnection as it develops its wind energy resource: the presence of isolated offshore wind farms will not help it to do so.

\section{References}

50 Hertz Transmission, Energinet.dk and Svenska Kraftnät (2010) Kriegers Flak Combined Grid Solution Feasibility Study, Berlin, 50 Hertz

Boyle, G. (2006) “Offshore Wind: the Enormous Potential”, Refocus, July-August, pp 26-29

BWEA and Garrad Hassan (2009) Charting the Right Course: Scenarios for offshore capital costs for the next five years, London, British Wind Energy Association. 
De Jonghe, C., L. Meeus and R. Belmans (2008) Power exchange price volatility analysis after one year of Trilateral Market Coupling, EEM 2008. 5th International Conference on European Electricity Markets

DECC and Ofgem (2009) Overview of Great Britain's Offshore Electricity Transmission Regulatory Regime: Joint DECC/Ofgem Statement, 17 June 2009 URN 09D/569, Ofgem ref: 67/09; London, Department of Energy and Climate Change

Drake, B. and K. Hubacek (2007) "What to expect from a greater geographic dispersion of wind farms? - A risk portfolio approach” Energy Policy, vol. 35, no. 8, pp. 3999-4008

European Commission (2007) Renewable Energy Road Map: Renewable Energies in the 21st Century: Building a More Sustainable Future: Impact Assessment. Accompanying document to the Communication from the Commission to the Council and the European Parliament. SEC(2006) 1719/3 Brussels, Commission of the European Communities

European Commission (2008) The Support of Electricity from Renewable Energy Sources: Accompanying Document to the Proposal for a Directive of the European Parliament and of the Council on the Promotion of the Use of Energy from Renewable Sources. SEC (2008) 57 Brussels, Commission of the European Communities

European Environment Agency (2009) Europe's onshore and offshore wind energy potential: An assessment of environmental and economic constraints, EEA Technical Report No. 6/2009 Copenhagen, European Environment Agency

European Wind Energy Association (2008) Pure Power: wind energy scenarios up to 2030, Available at www.ewea.org

European Wind Energy Association (2009) Wind Energy - The Facts, Brussels, European Wind Energy Association, available at www.ewea.org

Green, R.J. and N. Vasilakos (2010a) "Market Behaviour with Large Amounts of Intermittent Generation” Energy Policy, vol. 38, no. 7, pp. 3211-3220 
Green, R.J. and N. Vasilakos (2010b) Storing Wind for a Rainy Day: What kind of electricity does Denmark export? Department of Economics discussion paper 10-19, University of Birmingham

Green, R.J. and N. Vasilakos (2010c) The Long-term Impact of Wind Power on Electricity Prices and Generating Capacity, presented at the $11^{\text {th }}$ IAEE European Conference, Vilnius

Greenacre, P., R. Gross and P. Heptonstall (2010) Great Expectations: The Cost of Offshore Wind in UK Waters - Understanding the past and projecting the future, London, UK Energy Research Centre

House of Lords (2008) The Economics of Renewable Energy: Fourth Report of the Economic Affairs Committee, HL 195 of 2007-8

Klessmann, C., C. Nabe and K. Burges (2008) "Pros and cons of exposing renewables to electricity market risks - a comparison of the market integration approaches in Germany, Spain and the UK” Energy Policy, vol. 36, no. 6, pp. 3646-3661

Krohn, S., P.E. Morthorst and S. Awerbuch (2009) The Economics of Wind Energy: A report by the European Wind Energy Association Brussels, European Wind Energy Association

Milborrow, (2009) Managing Variability: A report to WWF-UK, RSPB, Greenpeace UK and Friends of the Earth EWNI, London, Greenpeace

Mackay, D.J.C. (2008) Sustainable Energy - Without the Hot Air, Cambridge, UIT.

Markard, J. and R. Petersen (2009) “The Offshore Trend: Structural Changes in the Wind Power Sector” Energy Policy vol. 37, no. 9, pp. 3545-3556

Munksgaard J. and P. E. Morthorst (2008), “Wind power in the Danish liberalised power market-Policy measures, price impact and investor incentives”, Energy Policy, Vol.36, no. 10, pp 3940-3947 
National Grid (2008) The Crown Estate Round 3 Offshore Wind Farm Connection Study, London, National Grid Company

Ofgem (2006) Transmission Price Control Review: Final Proposals, Ref 206/06, London, Office of Gas and Electricity Markets

Østergaard, P.A. (2008) “Geographic aggregation and wind power output variance in Denmark” Energy, vol. 33, no. 9, pp. 1453-1460

Ragwitz, M., A. Held, G. Resch, T. Faber, R. Haas, C. Huber, R. Coeanraads, M. Voogt, G. Reece, P.E. Morthorst, S.G. Jensen, I. Konstantinaviciute and B. Heyder, (2007) Assessment and Optimisation of Renewable Energy Support Schemes in the European Electricity Market, OPTRES Final Report, Karlsruhe, Fraunhofer IRB Verlag

Roques, F., C.Hiroux, and M. Saguan (2010) "Optimal wind power deployment in Europe--A portfolio approach," Energy Policy, vol. 38, no. 7, pp. 3245-3256

Sáenz de Miera G., P. del Río González, Ignacio Vizcaíno (2008) “Analysing the impact of renewable electricity support schemes on power prices: the case of wind electricity in Spain” Energy Policy, vol. 36, no. 9, pp. 3345-3359.

Sensfuß, F.; M. Ragwitz and M. Genoese (2008) “The Merit-order effect: A detailed analysis of the price effect of renewable electricity generation on spot market prices in Germany” Energy Policy, vol. 36, no. 8, pp. 3076-3084

Söderberg, D. and H. Weisbach, (2008) Service and Maintenance: Lillgrund Offshore Wind Farm, Stockholm, Swedish Energy Agency

Twomey, P. and K. Neuhoff (2010) “Wind power and market power in competitive markets” Energy Policy, vol. 37 no. 7, pp. 3198-3210 